\title{
Methods of ecological and economic optimization of land resource use in regional agri-food systems
}

\author{
S.O. Siptits, and N.E. Evdokimova* \\ All-Russian Institute of Agrarian Problems and Informatics named after A. A. Nikonov - Branch of \\ the Federal Research Center for Agricultural Economics and Social Development of Rural Territories \\ - VNIIESH, 107078 Moscow, Russian Federation
}

\begin{abstract}
Recent research on the assessment of agricultural policy results clearly shows that minimizing costs and maximizing profits, which have become the main criteria for agricultural producers in market conditions, do not lead to the sustainable functioning of regional agri-food systems (hereinafter referred to as AFS). The regime of sustainable production intensification is achieved through the synergy of three aspects of sustainability: environmental, economic and social. The purpose of this article is to present a new tool for optimizing and planning land use for the sustainable development of regional AFS. The application of these tools in practice is closely linked to the development of digitalization as a technological paradigm, within which appropriate information platforms should be created, as well as a regulatory framework that allows management bodies to promote environmentally and economically effective modes of territorial AFS operation.
\end{abstract}

\section{Introduction}

The management of agricultural systems is complex and depends on the biological and socio-economic conditions of each specific territorial unit. Recognizing this is crucial when developing tools to support decision-making. Recently, a number of tools, models and methodologies have appeared in foreign literature to support the design of AFS, for example, multi-stage, multi-purpose and multi-criteria land use optimization [1]. Many land use planning models support optimization:

1) sequence in the rotation and placement of crops to maximize farmers' profits while meeting the basic requirements set for improving biodiversity and preserving soil quality [2];

2) allocation of land and water resources to maximize productivity and minimize soil erosion and other environmental problems [3];

3) planning land-use changes by simulating their consequences and compromise solutions with nature protection and ecosystem services [4];

\footnotetext{
* Corresponding author: nevdoki@gmail.com
} 
4) land use management to adapt to climate change [5].

According to European agricultural policy makers, the success of developing appropriate tools and implementing them to address issues related to land use planning and optimization requires an approach based on the participation of agricultural producers, consultants, regional administrations and other relevant stakeholders in planning processes, as well as their participation in the evaluation of results [1].

When considering agri-food systems (AFS) at the regional level of the hierarchy, there is a need to take into account the territorial aspects associated with the placement of crop production in municipalities that are part of this region. Agri-food systems at the district level, as well as regional AFS, are territorial economic systems whose integral characteristics are formed from the results of economic activity of numerous producers of agricultural products. Such system organization, operating under the influence of market forces, is unable to provide rational use of land resources and agro-ecological potential of territories as a whole, leaving room for adjustments of the structure and properties of AFS in the region to increase its effectiveness and sustainability. The latter is closely related to soil fertility, the most important component of which is the content of organic matter in the active soil layer. The obvious contradiction between the manufacturer's desire to get the maximum economic effect from the exploitation of the AFS land resource, on the one hand, and the need to preserve its potential (read soil fertility), on the other, poses a rather complex methodological problem for the scientific community. Very conditionally in this problem it is possible to allocate two main tasks: improvement of design of production part of AFS and improvement of production activity management both on actually existing, and on the production subsystem being designed.

In hierarchically organized AFS, these tasks have their own specifics, depending on the level of economic systems consideration.

In this article, we will not consider the lower level - a separate commodity manufacturer in a highly competitive environment, for which various operational management and planning systems are currently being actively developed. These tools, integrated with aerospace technologies, precision farming systems, and agrometeorological forecasts, are focused on maximizing profits - the main competitive advantage of agri-food manufacturers.

Consider the possibilities of improving the super-system, in which there are many economic agents at the grassroots level. For it, along with the results of economic activity of economic agents, a significant criterion is the stability of the functioning of their set, which directly depends on the processes of reproduction of soil fertility.

For the considered super-system, the tasks of its design and management also have their own specifics. The solution of the first task is aimed at achieving such a configuration of the AFS, which ensures the most efficient use of the land resource of the territory for an indefinite period of time against the background of weather and climate dynamics. The way to do this - the content of the second task - is solved in the economy by developing (synthesizing) the so-called organizational and economic mechanism that creates a regulatory framework for stimulating and directing economic agents to achieve a project solution for the AFS configuration. In this paper, we will consider methods for solving the problem of designing a regional agri-food system, which can be used to obtain solutions that ensure the most efficient use of the land resource of the territory and, consequently, high commercial benefits of existing economic agents in combination with the reproduction of soil fertility. We will also show that the solution of such a problem, as well as its practical implementation, is accompanied by an increase in the volume of information and digital technologies used for this purpose. 


\section{Simulation results and their discussion}

Consider the classic problem of placing crop production in municipalities (districts) of the region. Each district has a unique combination of soil-climatic, organizational-economic and other characteristics, and a branch structure of crop production has been formed. This structure, that is, the distribution of acreage by cultivated crops, was created under the influence of market signals, it is local and does not take into account the relative advantages of other AFS at the district level. This structure is characterized by a wide range of variations in such important characteristics as the yield of crops of the same name, the cost of their production, which ultimately reduces the economic efficiency of the AFS of the region as a whole and, as a result, the efficiency of using the land resource of its territory.

Inject the following notation:

$I$ - range of municipal districts in the region;

$J_{n}$ - range of agricultural crops belonging to the $n$-th group (1 - perennial grasses, 2 continuous sowing crops, 3 - row crops, 4 - fallow area), $\cup J_{n}=J$

$\omega_{i j n}$ - sown area of the $j$-th agricultural crop belonging to the $n$-th group in the $i$-th district;

$G_{i}$ - content of mobile humus carbon in the arable soil horizon of the $i$-th district, $\%$;

$y_{i j}$ - average yield of the $j$-th crop in the $i$-th district;

$p_{j}$ - sales price of the $j$-th crop, thousand rubles/ton;

$p_{h i}$ - price of purchased or cost of own organic fertilizers in the $i$-th district.

$s_{i j}$ - average values of the total cost of the $j$-th crop, minus the cost of applying organic fertilizers, thousand rubles/ton;

$P R_{i}$ - average annual actual profit from all crop production sectors in the $i$-th district.

Taking into account the designations made, the simplest version of the problem of placing crop production, effective from the point of view of the ecological and economic criterion, for the regions of the region has the form:

$$
P R=\sum_{i \in I} \sum_{j \in J}\left(p_{j}-s_{i j}\right) y_{i j} \omega_{i j}-\sum_{i \in I} p_{h i} h_{i} \rightarrow \max
$$

$\sum_{j \in J} \omega_{i j}=\omega_{i}$

$\sum_{i \in I} \sum_{j \in J} \omega_{i j}=\omega$

$\sum_{j \in J}\left(p_{j}-s_{i j}\right) y_{i j} \omega_{i j} \geq P R_{i}, \forall i \in I$

$\omega_{i j}(1-\varepsilon) \leq \omega_{i j} \leq(1+\varepsilon) \omega_{i j}, \forall i \in I, \forall i \in I$

$$
\Delta G_{i}=k_{h i} h_{i}+1,02 \sum_{n=1}^{4} k_{n i} x_{n i}, \forall i \in I
$$

Where:

$\varepsilon$-permissible change in the acreage of agricultural crops in the districts,

$h_{i}$ - dose of organic fertilizers applied per hectare of crop rotation on average, $\mathrm{t} / \mathrm{ha}$,

$x_{n i}$ - Share of acreage, $\%$ in the $i$-th district belonging to the $n$-th class:

$$
x_{i n}=\frac{\sum_{j \in j_{n}} \omega_{i j n}}{\omega_{i}} 100, n=[1,4]
$$

The coefficients included in the equation of humus change have the following form:

$$
\mathrm{k}_{n \mathrm{i}}=\mathrm{k}_{\mathrm{ni}}^{*}\left[1-\exp \left(-\left(\mathrm{b}_{\mathrm{ni}}^{0}+\mathrm{b}_{\mathrm{ni}}^{1} \mathrm{C}\right)\right)\right.
$$

Parameters in (4) that depend on soil characteristics were estimated based on the results of a geographical network of experiments with fertilizers [6]. 
When solving the problem (1)-(4) productively, the branch structure of crop production is adjusted while maintaining the total sown area in the districts and the region as a whole. At the same time, each district receives an average marginal income from crop production in the amount of at least the actual amount, provided that the specified rates of reproduction of soil fertility are set $\Delta G_{i} \geq 0$.

To meet this condition, it is necessary to find the best economic combination of the following economic solutions: 1) increase the area of perennial grasses; 2) increase the dose of organic fertilizers; 3) reduce the area of row crops in the crop rotation. All these solutions negatively affect the profitability of crop production and, in most cases, can not stimulate economic agents, using intensive technologies.

However, there is a compromise solution zone in which the additional revenue generated by optimizing the industry structure can fully compensate or even exceed the losses from meeting the requirement for soil fertility reproduction.

Let the existing system of conducting agribusiness at the district level does not ensure the reproduction of soil fertility, which corresponds to $\Delta G_{i}^{*}<0$.Starting from the initial state, setting an increasing number of values for this parameter and solving (1)-(4), we get the dependence $P R_{i}=\varphi_{i}(\Delta G), i \in I$. Then the increase in the rate of change of soil humus and its new value can be estimated in a linear approximation:

$$
\begin{aligned}
& \vartheta_{i}=\frac{\alpha_{i}\left(P R_{i}-P R_{i}^{*}\right)}{b}, \alpha_{i} \leq 1 \\
& \Delta G_{i}=\Delta G_{i}^{*}+\vartheta_{i}
\end{aligned}
$$

Where $b$ - angular coefficient of linear approximation $\varphi_{i}(\Delta G)$,

$\alpha_{i}$ - share of profit growth received from optimizing the structure of sown areas and used to improve the conditions for the reproduction of soil fertility in the $i$-th district.

\section{Conclusion}

Rational use of land resources is a multi-factor problem. The current economic activity of agribusiness in a highly competitive environment does not encourage manufacturers to solve this problem. Nevertheless, objectively existing reserves for improving the efficiency of territorial agri-food systems allow to mitigate the contradictions that lie in the environmental and economic sphere.

The methods of AFS designing that are effective in environmental and economic terms are based on the procedures for optimizing the production and industry structure and other parameters of economic systems that exploit land resources. In this paper, the simplest deterministic economic and mathematical model that solves such a problem is considered. The inclusion of an equation that represents the dependence of the rate of change in the humus of the active soil layer on the ratio in crop rotation arrays of agricultural crops of different classes made it possible to obtain compromise solutions that do not infringe on the economic interests of commodity producers and do not reduce the production potential of the land resource.

It is important to note that the practical implementation of these methods is closely related to the development of digitalization as a technological paradigm, within which platforms should be created that integrate technical devices and methods for collecting heterogeneous information necessary to solve the task, software, and a regulatory framework that allows management bodies to promote environmentally and economically effective modes of territorial AFS operation. 


\section{Acknowledgment}

The article was prepared with the financial support of the Ministry of Education and Science of the Russian Federation as part of the implementation of agreement No. 075-152019-1939 dated December 10, 2019. Unique project identifier RFMEFI60719X0302.

\section{References}

1. P. Peltonen-Sainio, L. Jauhiainen, H. Laurila, J. Sorvali, E. Honkavaara, S. Wittke, M. Karjalainen, E. Puttonen, Land Use Policy 88, 104104 (2019) https://doi.org/10.1016/j.landusepol.2019.104104

2. F. Capitanescu, A. Marvuglia, G.T. Navarrete, E. Benetto, J. Clean. Prod., 147, 197205, (2017) 10.1016/j.jclepro.2017.01.076.

3. Á. Galán-Martín, P. Vaskan, A. Antón, L.J. Esteller, G. Guillén-Gosálbez, J. Clean, 140, 816-830 (2017) 10.1016/j.jclepro.2016.06.099

4. J.C.J. Groot, S.G. Yalew, W.A.H. Rossing, Urban Plan., 172(2018), 29-36, (2018) 10.1016/j.landurbplan.2017.12.008.

5. T. Klein, A. Holzkämper, P. Calanca, R. Seppelt, J. Fuhrer, Landscape Ecol., 28, 20292047, (2013) 10.1007/s10980-013-9939-0.

6. Regulation of the soil humus balance based on statistical research of the information base of long-term experiments (Moscow: VNIIMS n. a. D.N. Pryanishnikov, 1992) 